Jurnal Pemberdayaan: Publikasi Hasil Pengabdian kepada Masyarakat

Vol. 3, No. 2, Agustus 2019, Hal. 145-152

ISSN: 2580-2569; e-ISSN: 2656-0542

DOI: https://doi.org/10.12928/jp.v3i2.606

\title{
Menumbuhkan dan membentuk kepribadian sosial budaya masyarakat dalam mengelola pariwisata
}

\author{
Vani Dias Adiprabowo, Muhammad Yasir, Inana Dwi Arfiantiningrum, \\ Ardiansyah Sriaji Triwibowo
}

Universitas Ahmad Dahlan, Jl. Ring Road Selatan, Tamanan, Banguntapan, Bantul Yogyakarta 55166

Email: vanidias.uad@gmail.com

\begin{abstract}
ABSTRAK
Masalah pariwisata di Indonesia sekarang ini sangat memprihatinkan salah satunya terkait dengan menurunnya kepedulian dalam pengembangan objek wisata. Kuliah Kerja Nyata Universitas Ahmad Dahlan mengusung tema "Pengelolaan Pariwisata sebagai Upaya Peningkatan Ekonomi Masyarakat" yang tersebar di berbagai kabupaten di Jawa Tengah dan Daerah Istimewa Yogyakarta. Tema tersebut merupakan sikap taktis yang diambil UAD dalam menyikapi program pemerintah, yaitu Wonderful Indonesia — sebuah program kerja berbasis pariwisata. Setiap unit maupun divisi wajib membantu mendorong ekonomi masyarakat berbasis pariwisata melalui Program Kerja individu maupun bersama mereka. Untuk mencapai tujuan tema besar tersebut, beragam metode yang dilakukan, seperti berdiskusi dengan pengelola pariwisata, menulis jurnal pariwisata, pelatihan tourguide, dan pelatihan membuat video pariwisata. Melalui serangkaian metode tersebut, masyarakat secara signifikan dapat mempromosikan pariwisata melalui media sosial Blogspot, Facebook, Whatsapp, Intagram, dan sebagainya. Dampak nyata dari metode-metode tersebut adalah bertambahnya wisatawan lokal dan mancanegara yang berdatangan. Otomatis, tidak hanya masyarakat yang menjadikan pariwisata sebagai pekerjaan pokoknya yang mendapatkan keuntungan, namun pedagang, penganyam, dan peladang jagung pun mendapatkan keuntungan dari bertambahnya wisatawan lokal maupun mancanegara yang berdatangan setiap harinya.
\end{abstract}

Kata kunci: pariwisata, Jatisari, Puncak Becici, Pintu Langit

\begin{abstract}
The problem of tourism in Indonesia today is very alarming, one of which is related to the decline in awareness in the development of attractions. Kuliah Kerja Nyata Ahmad Dahlan University (UAD) Yogyakarta carries the theme "Tourism Management as an Effort to Improve the Economy of the Community" which is spread in various districts in Central Java and the Special Region of Yogyakarta. The big theme is a tactical attitude taken by UAD in addressing the government's program, Wonderful Indonesia-a tourism-based work program. Therefore, each unit and division is obliged to help drive the economy of tourism-based communities through the individual Work Program and with them. To achieve the objectives of the big theme, a variety of methods were carried out, such as discussions with tourism managers, writing tourism journals, tourguide training, and training on making tourism videos. Through a series of methods, the community can significantly promote tourism through social media Blogspot, Facebook, Whatsapp, Intagram, and so on. The real impact of these methods is the increase in local and foreign tourists arriving. Automatically, not only the people who make tourism as their main job benefit, but traders, weavers, and corn cultivators also benefit from the increase in local and foreign tourists who arrive every day.
\end{abstract}

Keywords: tourism, Jatisari, Puncak Becici, Pintu Langit 


\section{PENDAHULUAN}

Pariwisata atau turisme adalah suatu perjalanan yang dilakukan untuk rekreasi atau liburan dan persuapan yang dilakukan untuk aktivitas ini. Seorang wisatawan atau turis adalah seseorang yang melakukan perjalanan. Untuk saat ini, banyak negara bergantung pada banyaknya industri pariwisata sebagai sumber pajak dan pendapatan untuk perusahaan yang menjual jasa kepada wisatawan. Oleh karena itu, pengembangan industri pariwisata ini adalah salah satu strategi yang dipakai oleh organisasi nonpemerintah untuk mempromosikan wilayah tertentu sebagai daerah wisata untuk meningkatkan perdagangan melalui penjualan barang dan jasa kepada orang nonlokal atau mancanegara.

Menurut Undang-Undang Nomor 10 Tahun 2009 tentang Kepariwisataan, yang dimaksud dengan pariwisata adalah segala sesuatu yang didukung oleh berbagai macam kegiatan wisata yang didukung fasilitas serta layanan yang disediakan masyarakat pengusaha, pemerintah, dan pemerintah daerah.

Masalah pariwisata di Indonesia sekarang ini sangat memprihatinkan, di mana dengan mengikuti berkembangnya teknologi yang semakin pesat, dapat menyebabkan menurunnya kepedulian alam pengembangan objek wisata. Penyebab faktor tersebut adalah dengan tidak terlaksananya tujuh saptapesona, yang meliputi aman, tertib, bersih, sejuk, indah, ramahtamah, dan kenangan. Dalam membudidayakan ketujuh saptapesona tersebut, kadang kala membuat para pengunjung wisata (tourism) kurang nyaman, dalam hal ini disebabkan karena kekurang-hati-hatian. Penyebab semacam inilah yang mengakibatkan berkurang atau menurunnya pengunjung wisata di Indonesia.

Menurunnya juga para pengunjung wisata di Indonesia dikarenakan kurangnya mobilitas dan kualitas fasilitas yang lengkap, ditambah lagi dengan kurangnya akses komunikasi yang baik. Dalam hal ini, dibutuhkan orang-orang yang mumpuni, memadai, dan memiliki ketepatan waktu dan strategi pengelolaan sehingga pengunjung merasa nyaman.

Dengan menurunnya jumlah pariwisata di Indonesia, seharusnya membuat semua pengelola belajar dengan penuh, hal-hal apa yang perlu dipelajari dan dimetodekan. Dengan begitu, kepedulian dalam pelayanan menjadi baik. Oleh karena hanya dengan pelayanan, para pengunjung akan terikat hatinya untuk berkunjung kembali ke tempat wisata di mana ia harus kunjungi. Tidak hanya dilakukan oleh masyarakat saja, tentu harus ada kerja sama dengan pemerintah dalam rangka mendorong pembiayaan dalam pembangunan infrastruktur yang cukup dan memadai demi kenyamanan bersama. Selain itu, bagian terakhir dalam pembangunan pariwisata adalah bagaimana cara mempromosikan agar daerah dan objek wisata tersebut dikenal di dalam negeri maupun di luar negeri sehingga daerah tersebut dapat dikenal oleh mancanegara dan dunia. Hal itu merupakan salah satu tugas generasi muda (pelajar dan mahasiswa) sekarang ini agar maju di masa depan.

Selanjutnya, tujuan dari adanya program ini adalah (1) mengarsipkan sistem pengelolaan pariwisata; (2) memberikan nilai lebih bagi objek wisata; (3) menumbuhkan dan membentuk kepribadian sosial budaya masyarakat dalam mengelola pariwisata; (4) dan mempromosikan objek wisata guna membantu ekonomi masyarakat.

\section{METODE}

Kuliah Kerja Nyata Universitas Ahmad Dahlan Yogyakarta berlokasi di Dusun Seropan III, Gunung Cilik, dan Banjarharjo, Desa Muntuk, Kecamatan Dlingo, Kabupaten Bantul, Provinsi D.I. Metode pelaksanaan program yang digunakan adalah dengan berdiskusi dengan pengelola pariwisata, menulis jurnal pariwisata, pelatihan tourguide, dan pelatihan membuat video pariwisata.

Teknik pengumpulan data menggunakan teknik simak dan catat. Teknik simak disebut juga teknik sadap, yaitu penyadapan penggunaan bahasa secara tertulis yang dilakukan oleh seseorang untuk mendapatkan data (Mahsun, 2007). Data yang diperoleh berupa deskripsi 
mengenai objek wisata yang ada di Desa Muntuk, Dlingo, Bantul. Selanjutnya, teknik simak diikuti dengan teknik lanjutan yang berupa teknik catat (Mahsun, 2007). Teknik ini dilakukan dengan pencatatan terhadap objek data atau permasalahan yang diperoleh dari observasi maupun wawancara.

\section{HASIL, PEMBAHASAN, DAN DAMPAK}

Dalam pengabdian yang dilakukan oleh KKN Reguler Periode 71 Universitas Ahmad Dahlan Yogyakarta Unit VI.C yang dilaksanakan di Dukuh Seropan III, Gunung Cilik, dan Banjarharjo selama sebulan penuh, menghasilkan beberapa perubahan dalam sistem manajemen pengelolaan objek wisata. Hal ini memberikan kesadaran betapa pentingnya sosial budaya masyarakat dalam pengelolaan objek wisata guna memberikan kenyamanan bagi wisatawan yang berkunjung. Hasil tersebut akan dibagi menjadi tiga subhasil dari tiga divisi sebagai berikut.

\section{a. Puncak Ekowisata Jatisari}

Hal menarik dari Seropan III, selain sejarah terbentuknya adalah wisatanya. Ada sebuah tempat yang dijadikan objek wisata oleh masyarakat Seropan III, yaitu Ekowisata Puncak Jatisari. Konon, nama Puncak Jatisari diambil dari sebagian besar wilayah Seropan III yang ditumbuhi pohon jati. Tidak seperti objek wisata di Yogyakarta pada umumnya, Puncak Jatisari tidak hanya menawarkan pemandangan yang indah, namun juga sejarah gua yang terdapat di dalamnya dan kearifan lokal masyarakat yang masih sangat kental; terutama kerajinan tangan dari anyaman.

Jika Anda datang ke sini, Anda akan disambut oleh embusan angin yang kencang, hamparan sawah yang luas, dan hamparan gunung yang membatasi laut dan daratan. Tidak perlu khawatir dengan bayaran. Anda cukup membayar secara sukarela - kecuali hal lain yang dipilih; kamping, permainan, dan susur gua - yang tidak mungkin menghabiskan isi dompet Anda. Selain itu, di Puncak Jatisari juga terdapat sebuah batu yang disebut Batu Tompak, yang konon digunakan masyarakat untuk mengambil air ketika beristirahat di tengah perjalanan pergi maupun pulang dari sawah. Berikut salah satu spot foto yang berada di Puncak Jatisari. Dari gambar yang ada, jika pengunjung naik ke puncak pada pagi hari, ia akan merasa sedang berada di negeri atas awan. Puncak jatisari terlihat pada gambar 1.

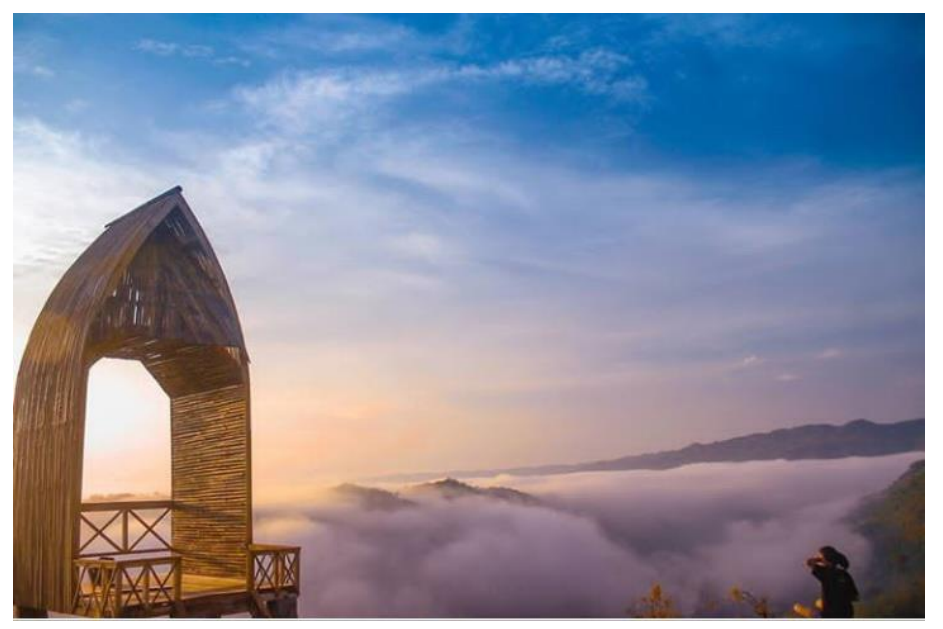

Gambar 1 Puncak Jatisari

Menurut Wakidi, seorang pengelola Ekowisata Puncak Jatisari, Puncak Jatisari merupakan objek wisata yang belum terekspos secara masif dan masih dikelola secara kooperatif oleh masyarakat, terutama karang taruna. 
"Ya, Mas, Puncak Jatisari kami kelola secara kooperatif. Sengaja memang, kami tidak mau ada campur tangan dari pemerintah terkait. Nanti urusannya menjadi ribet. Maka dari itu, kami bersepakat untuk membangun Puncak Jatisari ini dengan iuran. Adapun yang kami tawarkan kepada pengunjung beragam. Ada tempat santai, bermain, puncak, dan gua. Nah, gua itulah yang menjadi ikon Puncak Jatisari karena gua tersebut, seperti yang diceritakan oleh para tetua kampung, merupakan tempat pertapa dan persembunyian masyarakat dari penjajahan Jepang," tukasnya.

Letak Puncak Jatisari yang tidak begitu jauh dari Posko KKN atau rumah Pak Dukuh, persis di sebelah kanan gapura masuk Seropan III, membuat kami jika penat usai menjalankan program kerja, datang ke sana sekadar mengabadikan momen, meditasi, dan semacamnya. Benar apa yang dikatakan Wakidi, tempat ini benar-benar indah dan masih terjaga kelestariannya. Ya, kiranya Puncak Jatisari tepat untuk dijadikan tempat rekreasi keluarga.

Hari ini adalah hari ke-21 kami berada di Seropan III. Banyak hal yang kami dapat dan alami. Dari hal yang membuat kami senang, hingga menitikkan air mata. Sebentar lagi kami akan meninggalkan Seropan III yang menerima kami seperti anak-anaknya yang baru pulang dari perantauan. Di langit, awan mendung berarak tidak beraturan. Sebentar lagi, mungkin, hujan akan turun dan anak-anak Seropan III berlarian ke arah kami. Mengajak bermain atau sekadar ingin mendengar cerita. Bagaimana Seropan III sepuluh tahun lagi? Bagaimana anak-anak itu kelak? Apakah mereka masih mengingat nama kami? Waktu memang tidak bisa dihalangi jalannya.

\section{b. Di balik Pariwisata Puncak Becici Dusun Gunung Cilik}

Desa Muntuk, Kecamatan Dlingo, Kabubaten Bantul, terletak di arah timur dari Kota Bantul. Secara astronomis, Desa Muntuk terletak antara $07^{\circ} 53^{\prime} 15^{\prime \prime} \mathrm{LS}$ sampai 07'56'45',LS dan $110^{\circ} 25^{\prime} 50^{\prime}$ 'BT sampai $110^{\circ} 27^{\prime} 40^{\prime}$ 'BT. Luas Desa Muntuk adalah $13,7616 \mathrm{~km}^{2}$ atau 1376,16 ha.

Desa Muntuk ini terdiri dari sebelas dusun, salah satunya Dusun Gunung Cilik. Dusun Gunung Cilik yang mayoritas masyarakatnya petani dan pengrajin kayu memiliki keunikan sendiri. Bagaiamana tidak, masyarakat di dusun ini sangat aktif melakukan kegiatan apapun, salah satunya perkumpulan ibu-ibu yang terdiri dari beberapa RT yang mampu menghasilkan salah satu produk unggulan, yaitu wedang uwuh becici. Namun demikian, bukan wedang uwuh becici saja yang dihasilkan dari tangan-tangan perkumpulan ibu-ibu di sini karena masih banyak yang lainnya.

Salah satu bentuk keuletan dari ibu-ibu adalah mampu menghasilkan produk yang lainya, yaitu keripik singkong, keripik ubi ungu, dan keripik pisang. Selama KKN, kami mendampingi dan memberikan penyuluhan kepada masyarakat, khususnya ibu-ibu PKK yang tergabung dalam perkumpulan ibu-ibu dari beberapa RT yang diberi nama P2WKSS tentang mengemas dan memasarkan produk wedang uwuh becici dan keripik secara online.

Dusun Gunung Cilik juga memiliki tempat wisata yang tidak kalah indahnya dengan wisata-wisata yang lainnya, salah satunya Puncak Becici. Puncak Becici ini dulunya merupakan tempat menggembala sapi, namun seiring perkambangan zaman, Puncak Becici dijadikan sebagai objek wistata yang elok.

Objek wisata Puncak Becici ini memiliki pemandangan yang bagus dan indah. Melihat pemandangan dari atas Puncak Becici ini terasa terbang di atas awan. Puncak Becici merupakan salah satu objek wisata alam yang menawarkan pemandangan indah dari atas ketinggian. Para wisatawan dapat menikmati sejuknya pepohonan pinus yang dipadukan dengan pemandangan pedesaan dari atas bukit. Ketika berada di puncak, wisatawan akan dimanjakan dengan hijaunya perbukitan di wilayah Bantul dan sekitarnya 
dengan pandangan yang sangat luas dan terbuka. Para wisatawan yang berkunjung dapat menikmati indahnya golden sunrise, seperti pada gambar 2.

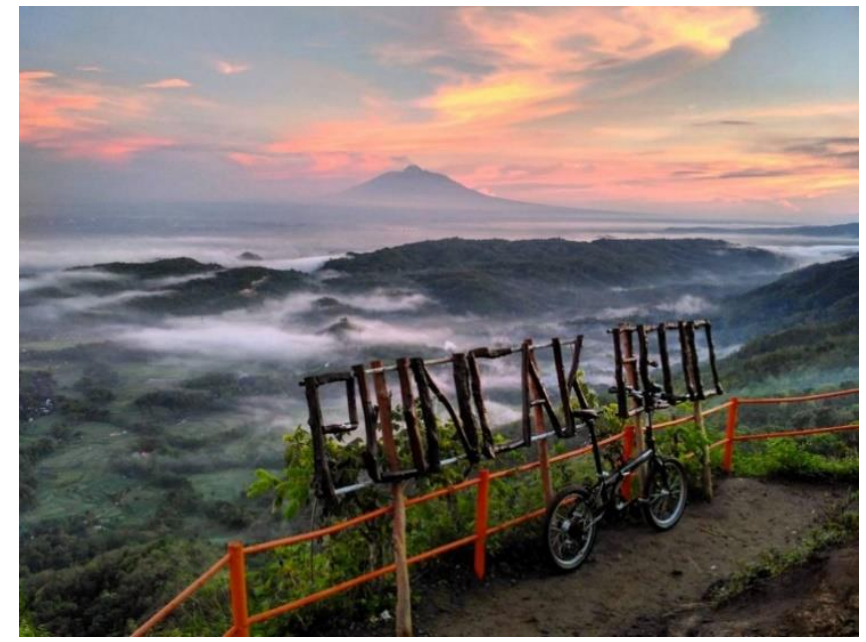

Gambar 2 Puncak Becici

\section{Wisata Pintu Langit}

Akhir-akhir ini, media sosial seperti instagram banyak mengunggah wisata alam yang cukup menjadi rekomendasi perjalanan. Kecamatan Dlingo, Kabupaten Bantul, misalnya, sebuah tempat yang berada di selatan Yogyakarta ini menjadi lokasi asyik untuk dikunjungi, apalagi jika wisata alamnya memiliki banyak spot kekinian.

Masyarakat Dlingo memang tidak pernah kehabisan ide kreatif untuk menciptakan wisata yang nge-hits dan instagramable. Salah satu wisata baru di Dlingo, yaitu Pintu Langit yang berada di Bukit Dahromo, Desa Muntuk, Kecamatan Dlingo, Kabupaten Bantul. Asal mula Pintu Langit menjadi objek wisata karena kreativitas masyarakat setempat yang ingin membuat spot pemandangan menjadi unik dan berbeda sehingga berdampak pada ekonomi masyarakat sekitar.

Bukit Dahromo sendiri adalah bukit yang bersebelahan dengan Bukit Mojo, yang terkenal dengan wisatanya yang bernama Bukit Lintang Sewu. Oleh sebab itu, Bukit Dahromo tidak mau ketinggalan dengan menghadirkan Pintu Langit. Jika sebelumya Dlingo terkenal dengan spot hutan pinus, adanya Pintu Langit ini cukup berbeda karena di tempat ini perpaduan deretan bukit hijau yang membentang tampak indah dan bisa menjadi spot foto yang menarik. Pintu Langit ini memiliki konsep yang menarik, yaitu sebuah pintu langit, di mana seolah-olah wisatawan yang berkunjung sedang membuka pintu menuju langit untuk melihat surga dunia. Dengan begitu, Pintu Langit menawarkan pemandangan ketika sunrise juga untuk melihat keindahan Yogyakarta di malam hari dengan berlatarkan lampu-lampu kota Yogyakarta dan langit yang dipenuhi bintang bertaburan. Selain sebuah pintu, ada juga spot foto piano putih yang tak kalah cantiknya dan masih ada beberapa spot-spot foto instagramable lainnya, seperti spot foto jendela putih dihiasi tanaman dengan background pepohonan hijau, seperti pada gambar 3. 


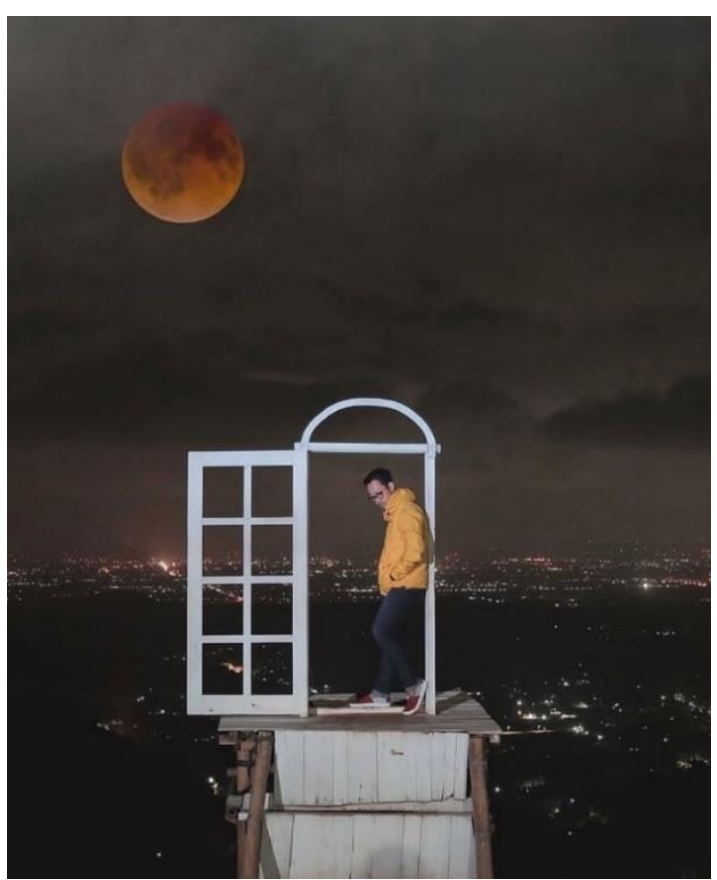

Gambar 3. Pintu Langit

Wisata Pintu Langit ini dikelola oleh masyarakat Tangkil dan Banjarharjo 1. Untuk menikmati keindahan tempat ini, pengunjung cukup membayar tiket masuk sebesar Rp5.000,00 per orang dan biaya parkir sebesar Rp2.000,00. Rute perjalanan menuju Pintu Langit cukup mudah diakses. Pengunjung tidak perlu khawatir, cukup aktifkan GPS di ponsel masing-masing ke arah taman wisata Bukit Lintang Sewu karena lokasinya yang berdekatan atau Gunakan Penduduk Sekitar (GPS).

Jika dilihat dari dampaknya, wisata Pintu langit memiliki dampak positif dan negatif. Dampak positifnya, yaitu wisata Pintu Langit dapat membantu perekonomian warga yang dulunya sebagai petani saja, kini juga usaha berjualan membuka warung di sekitar wisata. Dampak negatifnya, yaitu adanya pergaulan dari luar daerah dan cara berpakaian kekinian turis-turis yang sangat bisa ditirukan oleh pemuda atau remaja sekitar.

\section{SIMPULAN}

Berdasarkan pemaparan di atas, dapat disimpulkan bahwa terdapat beberapa objek wisata yang dapat meningkatkan perekonomian masyarakat sekitar di Desa Muntuk, Kecamatan Dlingo, Kabupaten Bantul, Provinsi D.I. Yogyakarta. Objek wisata tersebut meliputi Puncak Jatisari yang berlokasi di Dusun Seropan III, Puncak Becici yang berlokasi di Dusun Gunung Cilik, dan Pintu Langit yang berlokasi di Dusun Banjarharjo. Objek wisata yang telah disebutkan tersebut dikelola secara kooperatif dan cukup baik sehingga dapat meningkatkan taraf hidup masyarakat sekitar. Selanjutnya, perlu adanya peningkatan pengelolaan dari segi promosi, kebersihan, dan sebagainya, serta yang paling penting adalah tidak melupakan sejarah terbentuknya objek wisata tersebut, juga keramahtamahan penduduk sekitar. 


\section{DAFTAR PUSTAKA}

Badan Pengembangan dan Pembinaan Bahasa, Kementrian Pendidikan dan Kebudayaan Republik Indonesia. 2016. "Kamus Besar Bahasa Indonesia Edisi Kelima". Daring kbbi.kemdikbud.go.id, diakses pada 8 Agustus 2018.

Badan Pengembangan dan Pembinaan Bahasa, Kementrian Pendidikan dan Kebudayaan Republik Indonesia. 2016. Pedoman Umum Ejaan Bahasa Indonesia Edisi Keempat. Jakarta: Badan Pengembangan dan Pembinaan Bahasa.

Mahsun. 2007. Metode Penelitian Bahasa: Tahapan Strategi, Metode, dan Tekniknya. Jakarta: Rajawali Pers.

Undang-Undang Nomor 10 Tahun 2009 tentang Kepariwisataan 
